\title{
Evaluation of the risk to groundwater after treating logs with cypermethrin
}

\author{
Dimitri Dousse $\cdot$ Luiz Felippe de Alencastro • \\ Dominique Grandjean · Robert Jenni • \\ François Zwahlen
}

Received: 29 October 2012/ Accepted: 16 August 2014/Published online: 11 September 2014

(c) Springer-Verlag Berlin Heidelberg 2014

\begin{abstract}
In order to protect conifer logs against attacks from the striped ambrosia beetle (Trypodendron lineatum) during spring in Swiss forests, logs are treated with the insecticide cypermethrin. Rainfall can cause the insecticide to leach into the ground, potentially threatening the groundwater quality. Forest groundwater is widely used for drinking water, which means that any contaminants within it should be avoided. This study assesses the risk of groundwater contamination in field conditions. The two study areas are located on unconsolidated sediments (Censières, or CS) and on karstic rocks (Grand Bochat, or GB). An analytical method was developed to determine the concentration of cypermethrin and its degradation products 3-PBA and DCVA in water samples. Intensive rainfall was simulated in order to mimic a situation that threatens
\end{abstract}

D. Dousse $(\bowtie) \cdot$ F. Zwahlen

Center for Hydrogeology and Geothermics (CHYN), University

of Neuchâtel, Rue Emile-Argand 11, 2000 Neuchâtel,

Switzerland

e-mail: dimitri.dousse@gmail.com

F. Zwahlen

e-mail: francois.zwahlen@unine.ch

L. F. de Alencastro · D. Grandjean

Central Environmental Laboratory, School of Architecture, Civil and Environmental Engineering, Ecole Polytechnique Fédérale de Lausanne EPFL, Bâtiment GR Station 2, 1015 Lausanne, Switzerland

e-mail: felippe.dealencastro@epfl.ch

D. Grandjean

e-mail: dominique.grandjean@epfl.ch

R. Jenni

Bureau Nouvelle Forêt Sàrl, Rte de la Fonderie 8c,

1700 Fribourg, Switzerland

e-mail: jenni@nouvelleforet.ch groundwater. The study's results show that, when treated according to the manufacturer's instructions, a certain amount of insecticide was leached during the first rainfall event $(2.2 \mathrm{~g}$ or $4.4 \%$ of the applied cypermethrin). This leaching threatens groundwater quality, but can be avoided by decreasing the pesticide amount applied while maintaining a satisfactory protection. The insecticide amount that reached the groundwater was very low and was related to simulated rainfall, not natural rainfall. In Censières, only one groundwater sample presented a cypermethrin concentration $(4 \mu \mathrm{g} / \mathrm{l})$. In Grand Bochat, after a simulated rainfall of $36 \mathrm{~mm}, 3.3 \%$ of the insecticide ( $5 \mathrm{~g}$ ) was leached and $0.05 \%$ of the total applied insecticide amount (corresponding to $1.5 \%$ of the leached insecticide) reached the groundwater under the epikarst layer.

Keywords Cypermethrin - Logs - Insecticide treatment . Groundwater contamination

\section{Introduction}

Swiss forests are widely exploited for wood production, with the cutting of trees mainly occurring from November to March. Trees are then stored in stacks of logs, without branches but with the bark, generally next to the forest roads. From March to May, when the temperature increases, stacks of logs are vulnerable to attack by the striped ambrosia beetle (Trypodendron lineatum), which hollows out galleries inside the trunks to a depth of up to approximately $5 \mathrm{~cm}$ in which it lays its eggs. In Switzerland, one conifer, the spruce (Picea abies), is affected by this deterioration. The quality and value of the hollowed wood is reduced, which could cause economic losses of up to $50 \%$. To protect the spruce against beetle damage, a treatment 
with the insecticide cypermethrin is widely applied at the beginning of the spring.

Forest soils are generally well developed and rich with organic matter (Gobat et al. 2003) and allow good filtration of rain water. Atmospheric pollutants contained in the percolating water are held on the soil particles and the organic matter. Consequently, groundwater is particularly well protected in forests (Neary et al. 2009). Furthermore, while most forests in Switzerland are extensively exploited, the logging activity does not introduce a lot of pollutants and the soil quality is well preserved. The groundwater quality in forests is generally good and, in many regions, the spring water exploited for drinking water does not need any treatment. For these reasons, it is important to maintain the high groundwater quality.

During rainfall, and after treatment against the beetle, an amount of insecticide on the logs' surface could be solubilised in rainwater, drip from the logs into the ground, percolate in the subsurface, and potentially reach the groundwater. It is not known what amount of insecticide could flow from the wood, what amount could be retained in the soil, and what amount could reach the groundwater and finally a drinking water catchment. In order to avoid contaminating wells, Swiss laws protect the groundwater quality in the catchment area. It is forbidden to treat conifers logs with cypermethrin inside the inner protection zones (zone S in Switzerland). It is not known whether the protection zones are adapted to protect groundwater against an insecticide contamination. In unconsolidated sediments, the protection zone should define a perimeter in such a way that groundwater requires at least 10 days to flow from the outer boundary of the zone to the well (minimum $100 \mathrm{~m}$ ). In these regions, the protection zones are small areas around the wells and do not impose great restrictions for woodsmen. In karstic rocks the variations of flow velocities mean that the protection zones are determined based on local hydrogeological, geomorphological and pedological characteristics. In these regions, the protection zones recover enormous surfaces and the activities of woodsmen are highly restricted.

Cypermethrin in the environment is degraded by physical, chemical or biological processes (Calvet 2005). These processes create other molecules, called degradation products. The properties of these molecules, especially the toxicity, are not well known (World Health Organization, IPCS 1989). The present study proposed that the degradation products of cypermethrin have high toxicity and should not be found in drinking water. A laboratory analytical method was developed to analyse the cypermethrin and the main degradation products, the 3-phenoxybenzoic acid (3-PBA) and the 3-(2,2-dichlorovinyl)-2,2-dimethyl cyclopropanecarboxylic acid (DCVA) (Liu et al. 2007), in water samples. According to Swiss law, the groundwater is considered contaminated when the concentration of the pesticide or its relevant metabolites exceeds $0.1 \mu \mathrm{g} / \mathrm{l}$.

This study assesses, in field conditions, the contamination risk for groundwater water during the days after a cypermethrin treatment. A stack of logs was treated with cypermethrin in each of two study field sites that accurately represent the geological characteristics of unconsolidated sediments and karstic rocks. Water samples were collected between the $\operatorname{logs}$ and the ground to determine which insecticide amount was leached from the logs. Samples were also collected in the unsaturated zone of the soil and in groundwater in order to determine which insecticide amount could reach the groundwater and contaminate a well.

\section{General features of the studied areas}

\section{Geographical situation}

Two typical areas were chosen, one on unconsolidated sediments and one on karstic rocks. Most of the unconsolidated sediments in Switzerland are located on the Central Plateau and most of the karstic rocks in the Jura Mountains. Logging is an important economic activity in both regions. The first site, called "Censières" (CS), is located in the canton of Vaud, near the city of Lausanne on the Central Plateau (Fig. 1) at $900 \mathrm{~m}$ above sea level (Swiss Coordinate System: 543'990/158'280). The second site, called "Grand Bochat" (GB), is located in the canton of Neuchâtel, near the city of Neuchâtel in the Jura Mountains (Fig. 1) at $1,100 \mathrm{~m}$ above sea level (Swiss Coordinate System: 544'550/206'650).

\section{Hydrogeological situation}

The CS area subsoil, presented in Fig. 2a, is composed of a porous formation of unconsolidated sediments located on an impermeable molasse layer. At the treatment location, the thickness of the porous formation does not exceed $5 \mathrm{~m}$. A local aquifer develops in the unconsolidated sediments with a $4.7 \mathrm{~m}$ water table depth, the groundwater flow is controlled by the topography. A spring is located $160 \mathrm{~m}$ downstream site, at an altitude that is $18 \mathrm{~m}$ lower than the treatment site. Two piezometers are installed at, respectively, 15 and $60 \mathrm{~m}$ distance of the stack of logs between the treatment site and the spring, enabling it to reach the saturated zone of the aquifer. According to the protection zone, the treatment site should be located outside the spring's protection zone, although not outside of a hypothetical pumping that would take place in the piezometers. The insecticide leaching during rainfalls seeps vertically with the percolating water and could well reach the 
aquifer's saturated zone and then move with the groundwater to finally reach the piezometers and the spring.

The GB area, represented in Fig. 2b, is located on karstic rocks, which drains the percolating water very quickly. The hydrogeology of the area was already widely studied (Savoy 2007; Perrin 2003; Madec 1999). A cave goes down under $15 \mathrm{~m}$ of the epikarst. A known infiltration area,

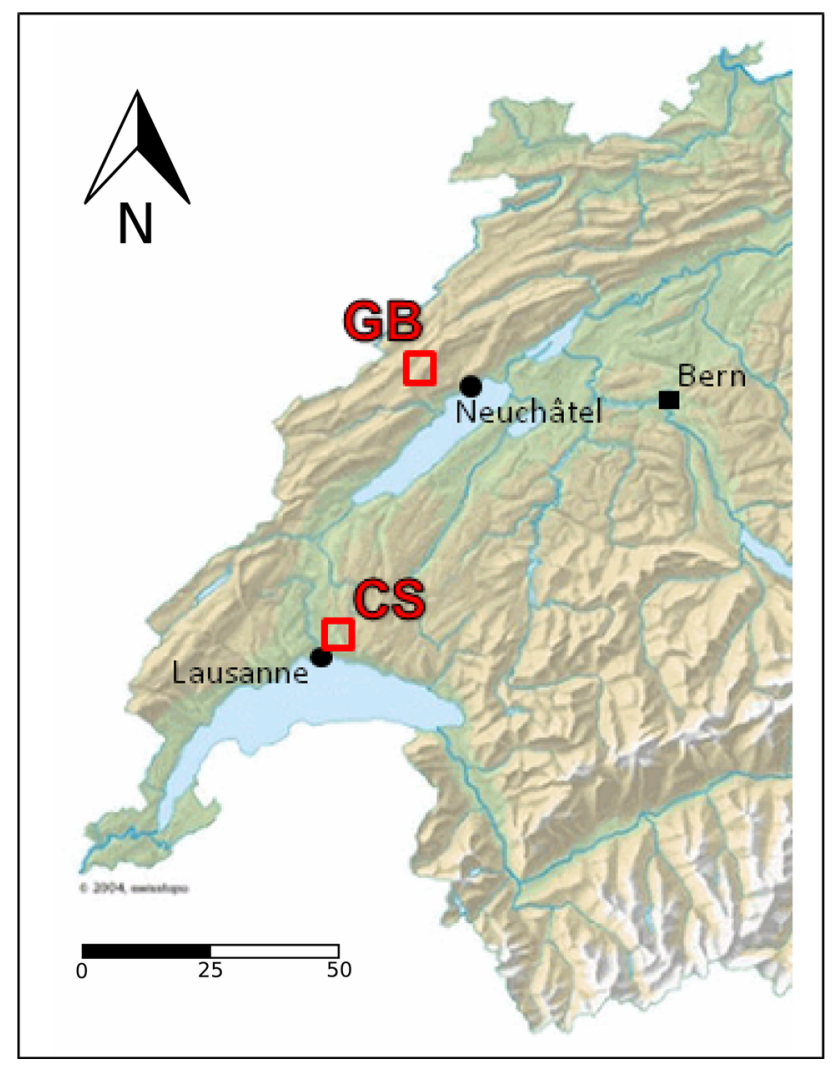

Fig. 1 Geographical situation of the studied areas (Swisstopo 2004). $C S$ Censières, on the Swiss Plateau, GB Grand Bochat, in the Jura Mountains where the place of treatment is located, is connected to the cave; an impermeable inclined layer turns the percolating water toward an outlet inside the cave. The water takes approximately $30 \mathrm{~min}$ to reach the cave. At the outlet, the groundwater drips from a surface of about $4 \mathrm{~m}^{2}$ in the ceiling. Accordingly, samples of water that cross the soil and the epikarst layer can be collected inside the cave. The water that drips from the cave ceiling infiltrates the cave floor and continues. All of the water infiltrated under the stack of logs is assumed to reach the outlet inside the cave (Madec 1999). This small hydrogeological system does not contain a permanent saturated zone.

\section{Pedological situation}

The soils of the studied sites are classified according to the World Reference Base of Soil Resources (IUSS Working Group 2006) and the humus layers are classified according to European Reference Base for Humus Form (Zanella et al. 2011). The soil of the CS area is a Haplic Cambisol (Dystric), which is representative of the main forest soils on the Central Plateau in Switzerland. It consists of four horizons (A, AS, S and C) according to the French Référentiel pédologique 2008 (Baize and Girard 2009). The first three horizons are rich in organic matter (3-10\%). The $\mathrm{pH}$ $(\mathrm{KCl})$ is around 4.5. The texture of horizons $\mathrm{A}, \mathrm{AS}$ and $\mathrm{S}$ is sandy loam and for horizon $\mathrm{C}$ it is loamy sand. The humus layer is a mull that is mainly composed of dead leaves. The soil is very homogenous and the infiltration can be considered constant.

The soil of GB area lies on a geological formation of limestone pavement (limestone eroded and cracked), which causes high heterogeneity. Three main different types of soil are formed according to the position on this substrate. In the cracks is Leptic Cambisol (Calcaric), up to $60 \mathrm{~cm}$ deep, which is composed of two horizons, A and B. This
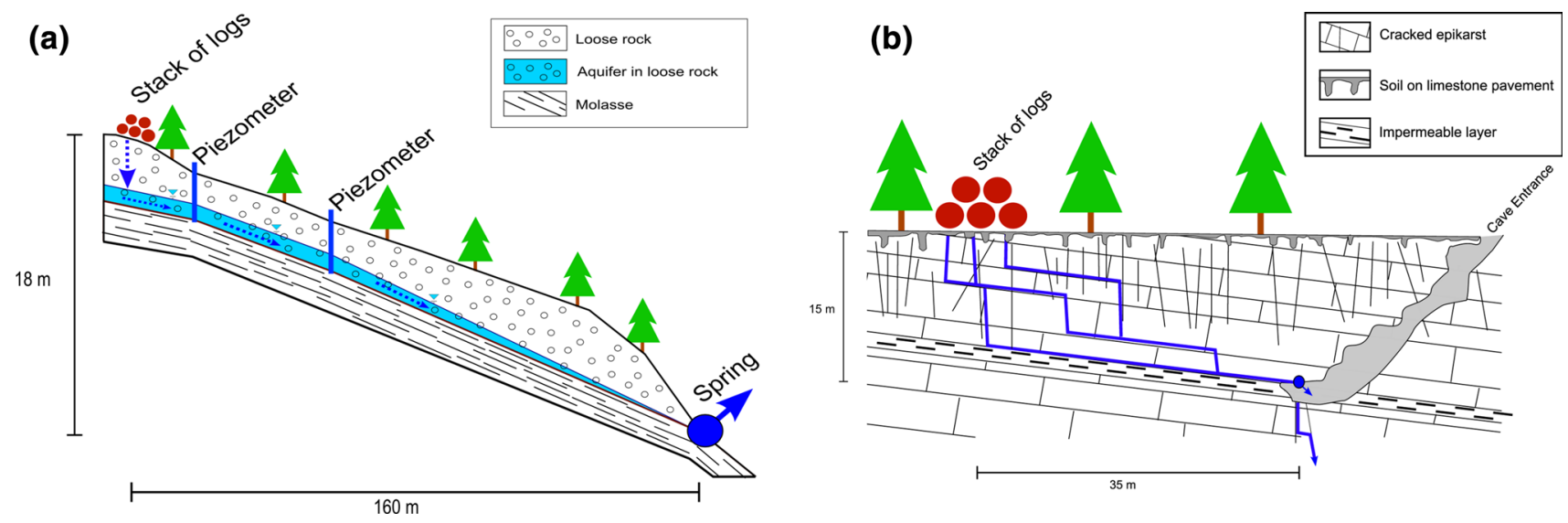

Fig. 2 a Cross-section of the study area CS. An aquifer is under the stack of logs on an impermeable layer of molasse. b Cross-section of the study area GB (Modified after Savoy 2007). The water infiltrated on the treatment site flows towards an outlet in a cave at a depth of $15 \mathrm{~m}$ 
soil is decarbonated, the texture is silty loam and the $\mathrm{pH}$ $(\mathrm{KCl})$ is between 6.0 and 6.8. Lithic, Folic Leptosol (Eutric) and Leptic Histosol (Eutric) are located on the flat areas between the cracks and are $5-20 \mathrm{~cm}$ thick. The humus layer types are dysmull and amphi.

\section{Materials and methods}

\section{Cypermethrin}

Cypermethrin is widely used to protect spruce logs against attacks by the striped ambrosia beetle. This insecticide belongs to the family of the synthetic pyrethroids, which contain the chemical active substance of pyrethrin. The properties that follow come from Liu et al. (2007), Oudou and Hansen (2002), Zhou and Rowland (1995) and the World Health Organization (World Health Organization, IPCS 1989). The chemical formula of cypermethrin is $\mathrm{C}_{22} \mathrm{H}_{19} \mathrm{O}_{3} \mathrm{NCl}_{2}$ and the molar mass is $416.3 \mathrm{~g}$. Cypermethrin is composed of eight stereoisomers. Cypermethrin is slightly soluble because the solubility in water is $4-10 \mu \mathrm{g} / \mathrm{l}$. The Henry constant is $2 \times 10^{-2} \mathrm{~Pa} \mathrm{~m}^{3} / \mathrm{mol}^{-1}$, which means that it is almost not volatile. The logarithm of its soil organic carbon water partitioning coefficient (log $K_{\text {oc }}$ ) is approximately 4.5 , which gives it a very high tendency to be adsorbed on the soil particles. The logarithm of cypermethrin's octanol-water partitioning coefficient (log $\left.K_{\text {ow }}\right)$ is around 5 , which means it tends to be accumulated in the living organisms. Cypermethrin does not remain in the soil for a long time and it is quickly degraded into other molecules because the half-life in the soil is between 7 and 50 days. According to these properties (high $K_{\mathrm{oc}}$ and $K_{\mathrm{ow}}$, and low half-life), cypermethrin is supposed to have a very low mobility in the environment. Cypermethrin is highly toxic for beetles, fishes and aquatic invertebrates (FribergJensen et al. 2003; Liu et al. 2005; Adam 2011). It is moderately toxic for humans by dermal adsorption or ingestion (German Federal Environment Agency 2005; Leng et al. 2003; Heudorf and Angerer 2001; Vijverberg and van den Bercken 1990).

In this study, the cypermethrin used to treat the logs is produced by the manufacturer Sintagro. It contains $100 \mathrm{mg} / \mathrm{l}$ of Zeta-cypermethrin ( $\zeta-C Y P$; CAS: 52315-07-8) and the rest of the product is composed of xylol (CAS: 1330-20-7). The $\zeta$-CYP is composed of four stereoisomers. It should be dissolved in water $(0.05 \%)$ before being applied to the logs according to the manufacturer's instructions.

Cypermethrin is degraded in the soil by physical, chemical and biological processes (Xie et al. 2008; Leng et al. 1998). The degradation pathway is illustrated in Fig. 3. The cypermethrin molecule is broken down into two degradation products, the $\alpha$-cyano-3-phenoxybenzyl alcohol, which reacts to produce 3-PBA, and the cis- or trans-3-(2,2-dichlorovinyl)-2,2-dimethylcyclopropane carboxylic acid (cis- and trans-DCVA), according to the isomer geometry. The properties of these molecules are not very well known because few studies have focused on the degradation products of pyrethroids in the environment (Xie et al. 2008). Nevertheless, they can be described as organic acids and, consequently, more soluble in water than cypermethrin. The acid's mobility in the soils depends on the soil $\mathrm{pH}$. The lower the $\mathrm{pH}$, the less mobile the organic acids. Their toxicity is also not well known. Based on the actual knowledge on the degradation products, it is hard to say whether the degradation products are more or less susceptible to contaminate groundwater than cypermethrin in the experimental conditions.

\section{Analysis of the compounds}

Standards of $\zeta$-CYP, 3-PBA and DCVA, as surrogate standards and derivatisation reagents, were obtained from Dr Ehrenstorfer Gmbh (Augsburg, Germany). The surrogate standards are used for recovery purposes and are the deuterated cypermethrin D6 (CYP D6) for the $\zeta$-CYP, the 2-phenoxybenzoic acid (2-PBA) for the 3-PBA and the 3-(2,2-dibromorovinyl)-2,2-dimethyl cyclopropanecarboxylic acid (DBVA) for the DCVA. The derivatisation reagent is the $N$-tert-butyldimethylsilyl- $N$-methyltrifluoroacetamide (MTBSTFA). The laboratory analytical method developed in this study is based on the methods of Adam (2011), Hladik et al. (2009) and Angerer and Ritter (1997).

All water samples were collected in glass bottles to prevent adsorption of cypermethrin (Hladik et al. 2009; Lee et al. 2002). The volume of the samples was approximately $250 \mathrm{ml}$. $\zeta$-CYP, 3-PBA and cis-and trans-DCVA concentrations are determined in water samples. Surrogates dissolved in methanol are added to the sample. $\zeta$-CYP is extracted by liquid-liquid extraction directly in the glass sampling bottle to avoid losses. Dichloromethane (DCM) is added and the sampling bottle is vigorously hand-shaken. After a short time, DCM, being at the bottom of the bottle, is recovered with a pipette. DCM is passed through anhydrous sodium and recovered in a balloon. This operation, from the DCM addition to the recovery in the balloon, is repeated two more times. DCM is then evaporated to dryness and recovered with $0.5 \mathrm{ml}$ of isooctane. The sample is injected in a gas chromatography-electron capture detector (GC-ECD) for the detection and quantification of $\zeta$-CYP. The GC-ECD is more sensitive than the gas chromatography-mass spectrometer (GC-MS) because chlorine atoms are present in the cypermethrin molecule (Fig. 3) and the GC-ECD is particularly sensitive to 
Fig. 3 Cypermethrin degradation in soil. The molecules analysed in this study are the cypermethrin, the 3-PBA and the cis- and trans-DCVA

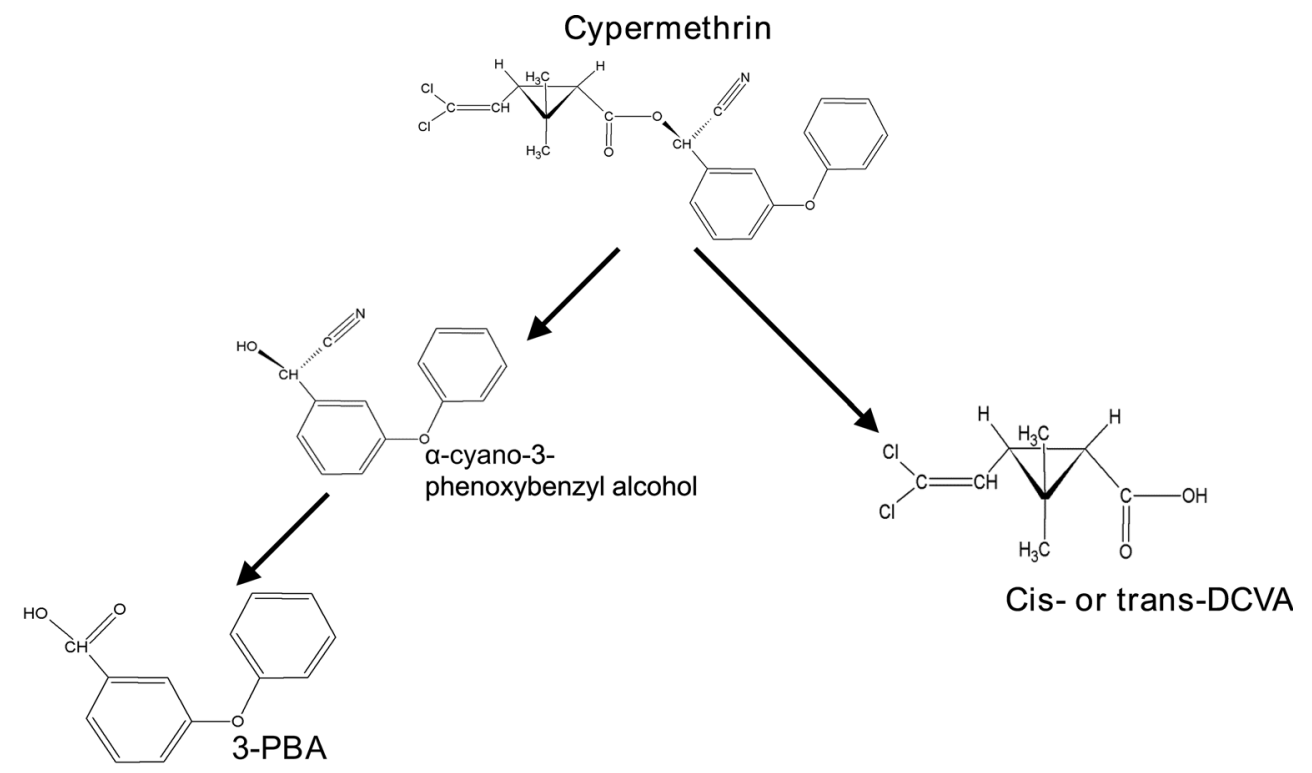

halogens. $\zeta$-CYP concentrations in the results are the sum of the four isomers.

The water that remains after the $\zeta$-CYP extraction by DCM is filtered and acidified with $\mathrm{HCl}$ to reach a $\mathrm{pH}$ between 2 and 2.5. The degradation products are extracted by solid phase extraction on a $\mathrm{C} 18$ cartridge of $6 \mathrm{ml}$. The elution is done with $6 \mathrm{ml}$ of DCM. The volume of the extract is then reduced to $1 \mathrm{ml}$ and $50 \mu \mathrm{l}$ of the derivatisation reagent, the MTBSTFA, is added. The derivatisation reaction was notably studied by Raeppel et al. (2011). The extract is put in an oven for $1 \mathrm{~h}$ at $60{ }^{\circ} \mathrm{C}$ and then evaporated to dryness and recovered with $0.5 \mathrm{ml}$ of isooctane. The sample is first injected in a GC-ECD for the detection of DCVA and then in a GC-MS for the detection of 3-PBA. The DCVA concentrations in the results are the sum of the cis- and trans-DCVA.

The analytical method was repeated three times, adding standards and surrogates in mineral water. The limits of detection with a sample of $250 \mathrm{ml}$ are 30,80 and $30 \mathrm{ng} / \mathrm{l}$ and the recuperation rates were $99.3 \pm 5,106.8 \pm 15$ and $110.5 \pm 8 \%$ for $\zeta$-CYP, 3-PBA and DCVA, respectively.

In soil samples, only $\zeta$-CYP was determined. After adding CYP D6 in $20 \mathrm{~g}$ soil samples, $\zeta$-CYP is extracted with DCM in a mechanical stirrer. Extracts are purified by adsorption chromatography on Florisil. $\zeta$-CYP is quantified by GC-ECD. The recuperation rate is $93.1 \%$ and the limit of detection is $0.7 \mathrm{ng} / \mathrm{g}$ (Adam 2011).

\section{Treatment of $\log s$}

At the CS site, according to the instructions given by the manufacturer during correspondence, a mixture of $0.45 \%$ of commercial product and $99.55 \%$ of water was prepared for the treatment and 2.51 of the mixture was applied to protect $1 \mathrm{~m}^{3}$ of wood. The concentration of application was $450 \mathrm{mg} / \mathrm{l}$ and $50 \mathrm{~g}$ of $\zeta$-CYP was applied on the $44 \mathrm{~m}^{3}$ of the stack of logs and introduced into the environment. Using this method, a large amount of insecticide dripped from the $\operatorname{logs}$ into the ground during the treatment. This amount polluted the soil and did not protect the wood against beetle attacks. The treatment was done on 21 April, 2010.

At the GB site, the treatment was applied according to the experience of the woodsmen of the city of Neuchâtel. To treat $30 \mathrm{~m}^{3}$ of conifers $\operatorname{logs}, 51$ of the mixture was used. Only $5 \mathrm{~g}$ of $\zeta$-CYP was applied and introduced into the environment. Using this method, the logs were impregnated and almost no insecticide dripped from the $\log$ s into the ground during the treatment. At the CS site, 7.5 times less $\zeta$-CYP per $\mathrm{m}^{3}$ of logs was applied than at the GB site. The treatment was done on 23 May, 2011.

\section{Rainfall characteristics}

Field experiments depend on the meteorology. Intensive rainfall was simulated in order to mimic threatening conditions for groundwater. In both experiments, the simulated rainfall was the first event that occurred after the treatment. The rain intensity was assumed to be constant across all the sprinkled area. The water used for the simulation was spring water, the $\mathrm{pH}$ of which ranged between 5.5 and 6 with $\mathrm{HCl}$. Natural rainfalls that occurred after the simulations did not reach the same intensity as the simulated rainfalls (Fig. 4).

At the CS site, the rain simulation installation consisted of a $3 \mathrm{~m}^{3}$ water tank, a pump and three rotating sprinklers. 
CS site
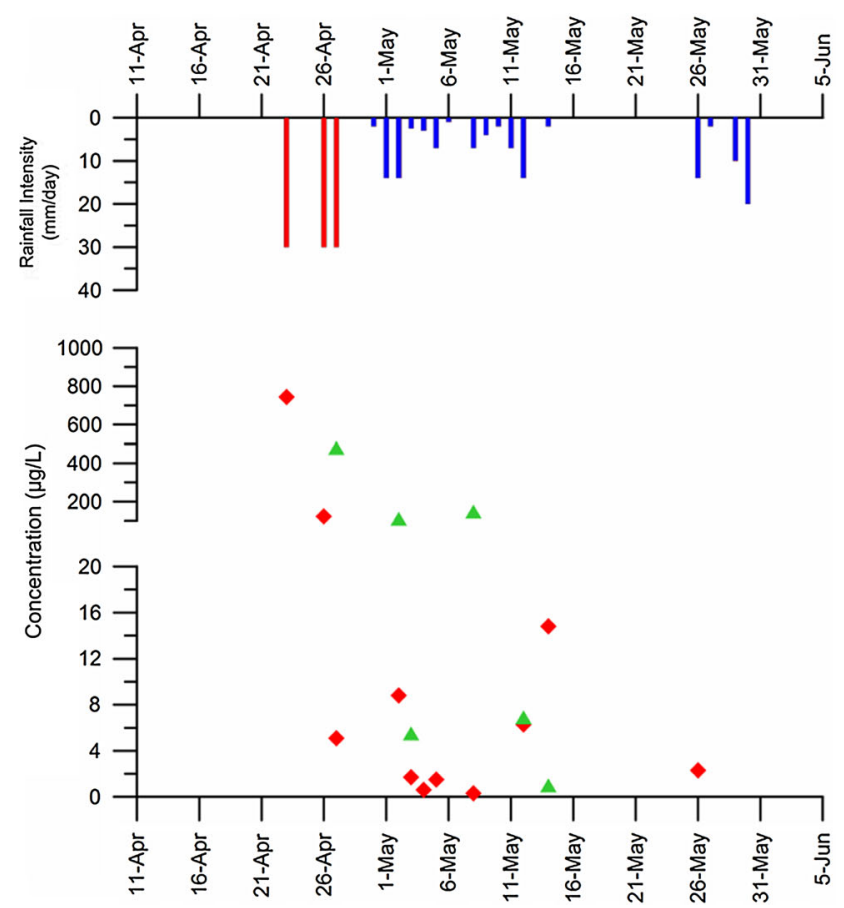

GB site

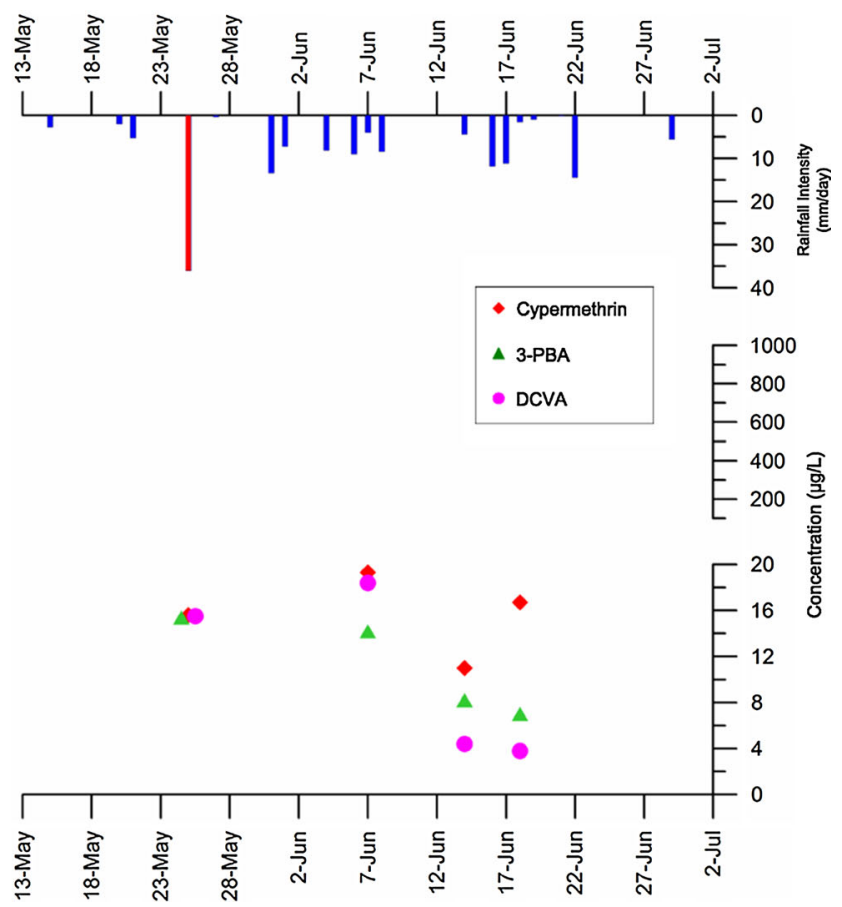

Fig. 4 Rainfalls and concentrations of $\zeta$-CYP, 3-PBA and DCVA (only at the GB site) in water dripping from the logs. The rainfalls in blue are the natural rainfalls. The rainfalls in red are the simulated rainfalls. The CS site is represented on the left and the GB site on the right

This system covered about $100 \mathrm{~m}^{2}$. Three rainfall events were simulated, on the 23rd, 26th and 27th of April, 2010. The first rainfall simulation was realised 2 days after the treatment. A rainfall intensity of $30 \mathrm{~mm} /$ day was applied on the $100 \mathrm{~m}^{2}$ at each rainfall simulation. At the GB site, the rain simulation system consisted in a pool of $4 \mathrm{~m}^{3}$ (with a tank to fill it), a pump and seven garden sprinklers arranged in hexagonal form. This installation covered about $150 \mathrm{~m}^{2}$. A rainfall intensity of $36 \mathrm{~mm} /$ day was applied on 25 May, 2011 in two parts, the first between 1245 and 1345 hours $(27 \mathrm{~mm})$ and the second, after filling the pool, between 1440 and 1500 hours $(9 \mathrm{~mm})$. After the rain simulation, excess water of the pool (around $2 \mathrm{~m}^{3}$ ) was emptied as far as possible from the pool. Unfortunately, the emptying place was connected to the outlet inside the cave and an outflow increase due to this operation was observed.

\section{Sampling}

Water samples were collected between the stack of logs and the soil surface, with a tarp at the CS site and a half pipe $15 \mathrm{~cm}$ of diameter at the GB site. To enable this, the stacks of $\operatorname{logs}$ were raised by about $50 \mathrm{~cm}$. The water collected represented the water that runs off the surface of the logs and dripped from the logs before arriving on the soil. Samples were collected after rainfall events.
Geibe et al. (2006) and Landon et al. (1999) studied the sample collection of soil water samples in the unsaturated zone. In order to collect soil water solution under the stack of logs, two stainless steel suction lysimeters were positioned 15 and $45 \mathrm{~cm}$ deep in the soil at the CS site and one was positioned $40 \mathrm{~cm}$ deep in the soil at the GB site inside a crack in the limestone pavement. The choice of stainless steel material instead of ceramic was necessary to avoid adsorption on the lysimeters. Samples were collected by applying a depression with a manual vacuum pump. The soil had to be very moist in order to collect samples.

At the CS site, groundwater samples were collected in the saturated zone of the aquifer in the piezometers and in the spring. With an automatic sampler, $25 \mathrm{ml}$ were collected every $2 \mathrm{~h}$ throughout a 24-h period in one sampling bottle. One sample was collected each day from the day after the treatment (22 April) until 15 May in the first piezometer; in the second piezometer from the day after the treatment (22 April) until 26 May; and from 27 days after the treatment (18 May) until 26 May in the spring. At the GB site, the groundwater dripping from the cave ceiling was caught with a tarp. This tarp was turned toward a gauged can, for which the ratio of water level/outflow was calibrated. The water level was measured continuously with a pressure transducer and the water flow was deducted from this high. The tarp was assumed to have caught the 
totality of the outflow. This system is based on the method used by Pronk et al. (2008). During the rain simulation experiment, nine samples were collected by hand, after which the samples were collected in the can with an automatic sampler. A total of $90 \mathrm{ml}$ of water were sampled every $2 \mathrm{~h}$ and put in the same sampling bottle on three separate occasions. Therefore, one sample is done each $6 \mathrm{~h}$. For protocol and financial reasons, it was not possible to analyse all the samples. The most interesting samples for groundwater contamination were those when the flow was maximal. Thanks to the measure of the flow, the samples corresponding to the maximal outflow in the cave can be identified.

At the end of each experiment, about one and half months after the treatment, four soil samples at the CS site and three at the GB site were sampled with an auger at different depths and the concentration of cypermethrin was determined in the laboratory. At the CS site, the soil sampling was repeated about 1 year after the treatment.

\section{Results}

Water dripping from the logs into the ground

At the CS site, only concentrations of $\zeta$-CYP and 3-PBA were determined. The $\zeta$-CYP concentration was greater during the first two simulated rainfalls (Fig. 4). The concentration is already much lower $(750 \mu \mathrm{g} / \mathrm{l}$ during the first rainfall) than the initial concentration during the treatment (450 mg/l). Assuming a constant concentration during the first rainfall, approximately $2.2 \mathrm{~g}$ of $\zeta$-CYP were leached, which corresponds to $4.4 \%$ of the total applied $\zeta$-CYP. Between the first and third rainfalls, the concentration of $\zeta$ CYP decreased drastically and then varied between 0.3 and $14.8 \mu \mathrm{g} / 1$. 3-PBA concentrations greater than $100 \mu \mathrm{g} / 1$ were also observed on 27 April (third simulated rainfall), 2 May and 8 May. Otherwise, the concentration varies between 1 and $7 \mu \mathrm{g} / \mathrm{l}$.

At the GB site, concentrations of $\zeta$-CYP, 3-PBA and DCVA were determined. The $\zeta-\mathrm{CYP}$ concentration was relatively stable throughout the study, at around $15 \mu \mathrm{g} / \mathrm{l}$. Note that water was not sampled at all rainfall events (only four samples were taken during the study). A small decrease of concentrations of 3-PBA and DCVA was observed between the beginning and the end of the study (Fig. 4). Contrary to the experiment at the CS site, concentrations greater than $100 \mu \mathrm{g} / \mathrm{l}$ during the first rainfall events were not observed. Knowing the water head of the rainfall simulated on the stack of $\log _{s}(36 \mathrm{~mm})$ and the surface recovered by the stack of $\operatorname{logs}$ and assuming a constant $\zeta$-CYP concentration in water dripping from the logs, the leached $\zeta$-CYP during the rain simulation was around $54 \mathrm{mg}$. The insecticide amount applied on the logs was $5 \mathrm{~g}$. The cypermethrin leached during the rainfall simulation experiment was $1.08 \%$ of the total applied $\zeta$ CYP.

Water in the unsaturated zone

Samples were collected with suction lysimeters in the unsaturated zone of the soil. This sampling methodology did not make it possible to collect a sufficient volume for microconcentrations analysis. The volume collected was always less than $50 \mathrm{ml}$ and charged with suspended matters. Under these conditions, the obtained results cannot be accurately interpreted.

\section{Groundwater}

At the CS site, 60 samples were collected in both piezometers and in the spring and concentrations of $\zeta$-CYP and 3-PBA were determined. Only one sample presented a significant concentration of $\zeta$-CYP $(4 \mu \mathrm{g} / \mathrm{l})$. This sample was collected on 26 April, 2010 in the first piezometer, which is installed $15 \mathrm{~m}$ from the bottom of the stack of logs, 3 days after the first rainfall simulation. The insecticide in this sample probably corresponded to the insecticide intensively leached during this rain. The water dripping from the $\operatorname{logs}$ presented a concentration around $750 \mu \mathrm{g} / \mathrm{l}$ and the adsorption process in the soil was not efficient enough to adsorb the totality of the $\zeta$-CYP before reaching the saturated zone of the aquifer. No 3-PBA was found in this sample, but the concentration in the water dripping from the logs during the first rainfall is unknown. The concentrations of $\zeta$-CYP and 3-PBA of the 59 other analysed samples were below the detection limit.

At the GB site, nine samples were collected during the simulated rainfall inside the cave and concentrations of $\zeta$ CYP, 3-PBA and DCVA were determined. The water transfer time through the epikarst layer was very short: an outflow increase was observed 39 min after the beginning of the rain simulation. The outflow measure inside the cave makes it possible to analyse water flow variations under the epikarst. Three flow peaks were observed (Fig. 5a): the two first were caused by the rain simulation, realised in two parts. The third peak was due to the emptying of the water excess of the pool. Unfortunately, the alimentation zone of the outlet inside the cave was not known perfectly and this emptying was done in this zone. The maximal ל-CYP concentration was $1.2 \mu \mathrm{g} / \mathrm{l}$ and was observed at almost the same time as the maximal flow due to simulated rain recharge (Fig. 5a). During the second flow peak, an increase of cypermethrin concentration was also observed. 


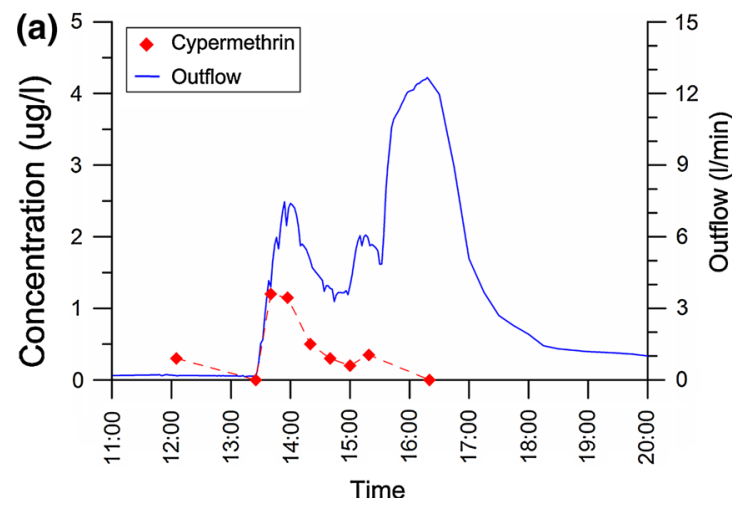

Fig. 5 a Cypermethrin concentration in water samples collected inside the cave at the GB site during the rain simulation experiment. The outflow is represented in blue. The third flow increase was due to the emptying of the excess water. The legal concentration limit for

Assuming a linear concentration evolution between two samples catching and knowing the output flow in the cave, the total cypermethrin amount found in the cave was calculated as $450 \mu \mathrm{g}$. The total applied cypermethrin was $5 \mathrm{~g}$ : cypermethrin found in the cave represented $9 \times 10^{-5}$ times the cypermethrin applied on the logs. It represented $0.8 \%$ of cypermethrin leached during this rainfall $(54 \mathrm{mg})$.

The maximal concentration for 3-PBA was almost the same as cypermethrin $(1.3 \mu \mathrm{g} / \mathrm{l})$ and the total amount found inside the cave during the experiment was calculated at $450 \mu \mathrm{g}$ (Fig. 5b). The maximal concentration arrived slightly before the maximal flow. The maximal concentration for DCVA was $4.3 \mu \mathrm{g} / \mathrm{l}$ and arrived at the same time as the maximal outflow. The adsorption in the soil seemed less effective for DCVA. In all, $1500 \mu \mathrm{g}$ of DCVA reached the outlet inside the cave during the rainfall simulation experiment.

Fourteen samples were analysed during the rest of the study. None presented a measurable concentration of $\zeta$ CYP, 3-PBA or DCVA, even though the concentration in water dripping from the logs was almost constant throughout the study. This observation was probably due to the fact that the totality of the infiltration zone connected to the outlet inside the cave is sprinkled during natural rainfalls, while only a small area was concerned by the simulation experiment. A certain insecticide amount probably reached the outlet inside the cave, although it was more diluted and the concentrations were below the detection limits.

Soil matrix

At the CS site, two soil cores were done with an auger: one took place in June 2010, one and half month after the

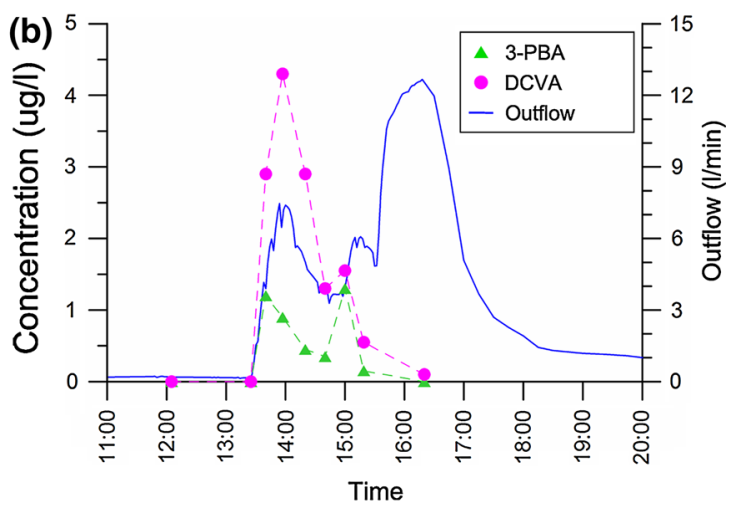

drinking water is $0.1 \mu \mathrm{g} / \mathrm{l}$. b Concentration of 3-PBA and DCVA in water samples collected inside the cave at the GB site during the rain simulation experiment

Table $1 \zeta$-CYP concentrations in soil samples at the CS site

\begin{tabular}{llr}
\hline Horizon & \multicolumn{2}{l}{$\begin{array}{l}\text { Concentration } \\
(\mu \mathrm{g} / \mathrm{kg})\end{array}$} \\
\cline { 2 - 3 } & 2010 & 2011 \\
\hline A $(0-10 \mathrm{~cm})$ & 77.5 & 25.3 \\
AS $(10-30 \mathrm{~cm})$ & 75 & 0.6 \\
S $(30-65 \mathrm{~cm})$ & 92.5 & 0.6 \\
C $(>65 \mathrm{~cm})$ & 45 & 2 \\
\hline
\end{tabular}

Table $2 \zeta$-CYP concentrations in soil samples at the GB site

\begin{tabular}{ll}
\hline Horizon & $\begin{array}{l}\text { Concentration } \\
(\mu \mathrm{g} / \mathrm{kg}) \\
2011\end{array}$ \\
\hline Humus & 10.6 \\
A $(0-45 \mathrm{~cm})$ & 13.8 \\
B $(>45 \mathrm{~cm})$ & 5.1 \\
\hline
\end{tabular}

treatment; and another in July 2011, 1 year after the treatment. One sample of each horizon was analysed and the $\zeta$-CYP concentration was determined. The results are presented in Table 1. $\zeta$-CYP was indeed adsorbed in the soil, which explains why only small concentrations are found in groundwater. The $\zeta$-CYP concentrations decreased 1 year after the treatment, but a certain amount was always present in the soil. The degradation rate was not efficient enough to eliminate the total insecticide amount.

At the GB site, a soil core was also done one and half month after the treatment (see Table 2 for results). Concentrations were lower than at the CS site, probably because of the insecticide amount applied during the treatment, which was indeed lower at the GB site than at the CS site. Cypermethrin adsorption took place mainly in the humus layer and in the horizon A. 


\section{Discussion}

Water dripping from the logs into the ground

The main difference between the two experiments was the greater concentrations of $\zeta$-CYP and 3-PBA observed at the CS site, which did not occur at the GB site. This difference was probably due to the way the treatment was conducted and the amount of insecticide applied. At the CS site, 7.5 times more $\zeta$-CYP was applied per $\mathrm{m}^{3}$ of $\operatorname{logs}$ than at the GB site. A higher amount was leached during the first rainfall event at CS site; this leaching can be decreased by treating it with less insecticide, as at GB site. Note that the protection against the beetle was also as effective as at the GB site.

The $\zeta$-CYP degradation seemed to occur on the logs. The degradation products were found in the water dripping from the $\operatorname{logs}$ throughout the study. The commercial product used in this study probably contained degradation products, because the higher concentrations were observed at the beginning of the experiments.

Repartition of the cypermethrin between the different mediums

It was possible to calculate the repartition of the cypermethrin and its degradation products between the different mediums (on the logs' surface, on soil particles and in groundwater) after the rain simulation of $36 \mathrm{~mm}$ at the GB site. To calculate this repartition, taking into account the degradation products, the degradation products amounts were added to the $\zeta$-CYP amount. After the rain simulation experiment, $3.3 \%$ of the applied cypermethrin dripped into the ground and $0.05 \%$ reached the groundwater. About $98.5 \%$ of the leached insecticide was retained in the soil, while $96.7 \%$ of the total amount was not leached and probably stayed on the log surface.

The distribution of cypermethrin between groundwater and soil depends on many parameters, and in particular the hydrogeological situation, the soil $\mathrm{pH}$ and composition, the organic matter content and the groundwater composition. Cypermethrin concentrations in the groundwater below the karstic rocks were significantly higher in the experiments than groundwater below the porous subsoil. However, it was not possible to define a significant relationship between the other measured parameters and the distribution of cypermethrin between the different mediums. Although it was not specifically evaluated, the hydrogeological conditions may have the largest influence on the transport of cypermethrin from the soil to groundwater.
Contamination of drinking water?

Based on the obtained results, it is presumed that the risk of drinking water contamination by $\zeta$-CYP (according the Swiss law $(0.1 \mu \mathrm{g} / \mathrm{l})$ is low under the present conditions in the experimental sites. In the experiments, an amount of insecticide reached the groundwater and sometimes exceeded $0.1 \mu \mathrm{g} / \mathrm{l}$. However, the pesticide was never found in potential catchments. At the CS site, cypermethrin was only found in the first piezometer, near the treatment site, and never in the other piezometer nor in the spring. If the water had been caught in the spring, no drinking water contamination would have occurred. Moreover, the insecticide found in groundwater samples was never found after natural rainfalls, but after artificial events only. Natural rainfalls probably dilute the pesticide and the concentration reduces to below the detection limit. Even in a very vulnerable situation, such as that of karstic rocks at the GB site, it represents only a small ratio, the greater amount of infiltrated pesticide not crossing the soil layer (99.2\%).

The experiments described in this study were achieved while strictly abiding the manufacturer's instructions (GB site) or using less pesticide (CS site). In the CS site experiments, the protection against beetles was successful. It is important to abide the instructions and to not to increase the applied pesticide. It does not necessarily improve the protection, but it could increase the percolating amount and the risk to groundwater.

\section{Conclusion}

This study observed that the main cypermethrin amount was not leached and did not threaten groundwater. By applying the recommendations of the manufacturer, a certain insecticide amount was leached into the ground during the treatment and the first rainfall $(4.4 \%$ of the applied insecticide). Decreasing the insecticide amount applied-as at the GB site, where 7.5 times less $\zeta$-CYP per $\mathrm{m}^{3}$ of logs is used than at the CS site-the leaching during the first rainfall decreased significantly. In this case, after a simulated rainfall of $36,165 \mathrm{mg}$ of insecticide (or $3.3 \%$ of the total insecticide amount) dripped from the logs. Using this method, protection against the beetle was also effective. Thus, the treatment method also has an influence and it is possible to minimise the cypermethrin leaching into the soil by decreasing the amount of insecticide applied.

Cypermethrin is well adsorbed in the soil. The concentrations found in the aquifer at the CS site and under the epikarst at GB site are much lower than the concentration in leached water. Degradation products also appear to be well adsorbed. At the CS site, 3-PBA was never found in 
the aquifer; at the GB site, concentrations of 3-PBA and DCVA were much lower in water dripping from the logs. The mobility of both of degradation products depends on the acidity of the soil, although the adsorption always seems to occur in the soil at GB site with a pH between 6 and 6.8. The cypermethrin adsorption was confirmed by the soil core samples presenting cypermethrin concentrations at the end of the experiments.

Finally, in porous media, the amount of insecticide that can reach the aquifer is very low. Therefore, the risk to groundwater used for drinking water is very low after treating the logs with cypermethrin respecting the restrictions in the protection zones. In karstic media, the experiment realised in this study shows that cypermethrin and its degradation products can reach the groundwater, but the amount is very low and the main amount is retained in the soil, despite the vulnerability of the system.

Acknowledgments The authors would like to thank the "Service des parcs et domains" of the city of Lausanne and the "Service des forêts" of the city of Neuchâtel, which permitted and actively supported the realisation of the experiments on the studied areas Censières and Grand Bochat, and also lent materials and made employees available to assist. Thanks are also due to the Soil \& Vegetation Laboratory of the University of Neuchâtel for the soil analysis. This research was funded by the Alpeau project, which is a part of the France-Switzerland Interreg programme of territorial cooperation.

\section{References}

Adam O (2011) Bioindication de la qualité de l'eau pas les gammares: Concepts et applications. Presses universitaires de FrancheComté, Université de Franche-Comté

Angerer J, Ritter A (1997) Determination of pyrethroid metabolites in human urine using solid-phase extraction and gas chromatography-mass-spectrometry. J Chromatogr 695:217-226

Baize D, Girard MC (2009) Référentiel pédologique 2008. Editions Quæ, Versailles

Calvet R (2005) Les pesticides dans les sols, Conséquences agronomiques et environnementales. France Agricole Editions, Paris

Friberg-Jensen U, Wendt-Rasch L, Woin P, Christoffersen K (2003) Effects of the pyrethroid insecticide, cypermethrin, on a freshwater community studied under field conditions. I. Direct and indirect effects on abundance measures of organisms at different trophic levels. Aquat Toxicol 63:357-371

Geibe CE, Danielsson R, van Hees PAW, Lundström Ulla S (2006) Comparison of soil solution chemistry sampled by centrifugation, two types of suction lysimeters and zero-tension lysimeters. Appl Geochem 21:2096-2111

German Federal Environment Agency (2005) Internal pyrethroid exposure among the general population in Germany and reference values for pyrethroid metabolites in urine. Bundesgesundheitsbl-Gesundheitsforsch-Gesundheitsschutz 48:1187-1193

Gobat JM, Aragno M, Matthey W (2003) Le sol vivant, Base de pédologie-Biologie des sols. Presse polytechnique et universitaire romande, Lausanne
Heudorf U, Angerer J (2001) Metabolites of pyrethroid insecticides in urine specimens: current exposure in an urban population in Germany. Environ Health Perspect 109:213-217

Hladik ML, Smalling KL, Kuivila KM (2009) Methods of analysisDetermination of pyrethroid insecticides in water and sediment using gas chromatography/mass spectrometry, U.S. Geological Survey Techniques and Methods 5-C2

IUSS Working Group WRB (2006) World reference base for soil resources 2006. World Soil Resources Reports No.103. FAO, Rome

Landon MK, Delin GN, Komor SC, Regan CP (1999) Comparison of the stable-isotopic composition of soil water collected from suction lysimeters, wick samplers and cores in a sandy unsaturated zone. J Hydrol 224:45-54

Lee S, Gan J, Kavashima J (2002) Recovery of synthetic pyrethroids in water samples during storage and extraction. J Agric Food Chem 50:7194-7198

Leng G, Kühn KH, Idel H (1998) Biological monitoring of pyrethroids in blood and pyrethroid metabolites in urine: applications and limitations. Sci Total Environ 199:173-181

Leng G, Ranft U, Sugiri K, Hadnagy W, Berger-Preiss E, Idel H (2003) Pyrethroids used indoors-biological monitoring of exposure to pyrethroids following an indoor pest control operation. Int J Hyg Environ Health 2006(2):85-92

Liu W, Gan JJ, Qin S (2005) Separation and aquatic toxicity of enantiomers of synthetic pyrethroid insecticides. Chirality 17:127-133

Liu TF, Sun C, Ta N, Hong J, Yang SG, Chen CX (2007) Effect of copper on the degradation of pesticides cypermethrin and cyhalothrin. J Environ Sci 19:1235-1238

Madec G (1999) Etude des écoulements dans l'épikarst. Approche géophysique, hydraulique et hydrochimique sur le site de GrandBochat. MSc thesis, Centre of Hydrogeology, Neuchâtel

Neary DG, Ice GG, Jackson CR (2009) Linkages between forest soils and water quality and quantity. For Ecol Manage 258:2269-2281

Oudou HC, Hansen HC (2002) Sorption of lambda-cyhalothrin, cypermethrin, deltamethrin and fenvalerate to quartz, corundum, kaolinite and montmorillonite. Chemosphere 49:1285-1294

Perrin J (2003) A conceptual model of flow and transport in a karst aquifer based on spatial and temporal variations of natural tracers. Thesis, University of Neuchâtel, Switzerland

Pronk M, Goldscheider N, Zopfi J, Zwahlen F (2008) Percolation and particle transport in the unsaturated zone of a karst aquifer. Ground Water 47:361-369

Raeppel C, Nief M, Fabritius M, Racault L, Appenzeller BM, Millet M (2011) Simultaneous analysis of pesticides from different chemical classes by using a derivatisation step and gas chromatography-mass spectrometry. J Chromatogr A 1218:8123-8129

Savoy L (2007) Use of natural and artificial reactive tracers to investigate the transfer of solutes in karst systems. Thesis, University of Neuchâtel, Switzerland

Vijverberg HPM, van den Bercken J (1990) Neurotoxicological effects and the mode of action of pyrethroid insecticides. Crit Rev Toxicol 21:105-126

World Health Organization, IPCS (1989) Environmental Health Criteria 82. WHO, Geneva

Xie WJ, Zhou JM, Wang HY, Chen XQ (2008) Effect of nitrogen on the degradation of cypermethrin and its metabolite 3-phenoxybenzoic acid in soil. Pedosphere 18:638-644

Zanella A et al (2011) European Humus Forms Reference Base, hal00541496, version 2

Zhou JL, Rowland SJ (1995) Influence of the nature of particulate organic matter on the sorption of cypermethrin: implications on $\mathrm{K}_{\mathrm{OC}}$ correlations. Environ Int 21:187-195 